\title{
Seismic activity reduction with the use of blasting and passive seismic tomography control, a case study from copper ore mine, Poland
}

\author{
A. B. Gogolewska ${ }^{1}$ (D) D. Smolak ${ }^{2}$
}

Received: 18 September 2020 / Accepted: 28 January 2021 / Published online: 12 February 2021

(c) The Author(s) 2021

\begin{abstract}
Deep copper ore mines in Poland have been struggling with seismic hazard since almost fifty years ago when the first rock burst occurred. Increasing exploitation depth and mined-out space make the mining conditions constrained and severe causing the seismic activity to grow substantially. Consequently, rock burst preventive activities have to be incorporated into mining technology to provide work safety. To date, the group winning blasting has posed the most commonly used preventive measure, so its efficiency in seismic energy reduction is of significant importance for the rock burst hazard mitigation. The more energy blasting works provoke to release the safer the work environment gets. The article aimed to assess the efficiency of such an energy reduction, which was approached in two ways. Firstly, the drop of energy and in turn its reduction efficiency was assessed simply using a percentage of provoked tremors' energy and number. Next, the analysis employed passive seismic tomography results to find if provoked tremors took place in high-velocity zones. The analysis made it possible to verify the assumption that the more provoked energy occurs in such zones the more successful preventive blasting is.
\end{abstract}

Keywords Seismic hazard · Induced seismic activity $\cdot$ Passive seismic tomography $\cdot$ Active rock burst prevention

\section{Introduction}

In Poland, copper ores have been excavated in the southwest part of the country, in three deep mines: Lubin, Rudna and Polkowice-Sieroszowice, owned by the KGHM Polska Miedz S.A. (Fig. 1), for about fifty years. Since the very beginning, tremors and rock bursts have been the most dangerous and unpredictable underground hazard (Gibowicz 2009; Butra 2010). Many seismic techniques have been implemented to recognise and monitor the seismic and rock burst hazard in mining (e.g. Kormendi et al. 1986; Gibowicz and Kijko 1994; Dubinski et al. 2001; Szreder et al.

Communicated by Michal Malinowski (CO-EDITOR-INCHIEF)\Zenon Pilecki (Guest Editor).

$\triangle$ A. B. Gogolewska

anna.gogolewska@pwr.edu.pl

D. Smolak

smolakdaria@wp.pl

1 Department of Mining and Geodesy, Wroclaw University of Science and Technology, Wroclaw, Poland

2 Hydrotechnical Department, KGHM Polish Copper JSC, Lubin, Poland
2008; Czarny et al. 2016; Marcak and Pilecki 2019). Seismic events are the result of the rock mass instability (Aki and Richards 2009). Tremors or rock bursts induced by mining are called spontaneous. While those caused by winningblasting works are called blasting-induced or provoked, which means that they are triggered on purpose to release energy and hence to reduce the stress accumulated within the rock mass.

The first rock burst took place at the beginning of the 1970s in the Polkowice-Sieroszowice mine (Fig. 1). Since then a lot of research methods have been employed to recognise, reduce and monitor the seismic and rock burst hazard (Dubinski et al. 2001; Mutke et al. 2001; Kijewski 2006; Butra 2010; Czarny et al. 2019). Therefore, forecasting the areas where they occur plays an important role in work safety maintenance. To date, passive seismic tomography has been successfully used to forecast the location of stress concentration zones, which may form areas of increased seismic activity. Such zones can be defined based on seismic events registered over a certain period before mining operations begin (Maxwell and Young 1993, 1994; Nolet 1987; Mutke et al. 2001; Debski 2002, 2010, 2013; Debski et al. 2018). A high seismic hazard is manifested by the velocity gradient of a longitudinal seismic wave and calculated 
Fig. 1 The Polkowice-Sieroszowice, Rudna and Lubin copper ore mines in the south-west of Poland. Mining areas of the Polkowice-Sieroszowice mine are marked in yellow

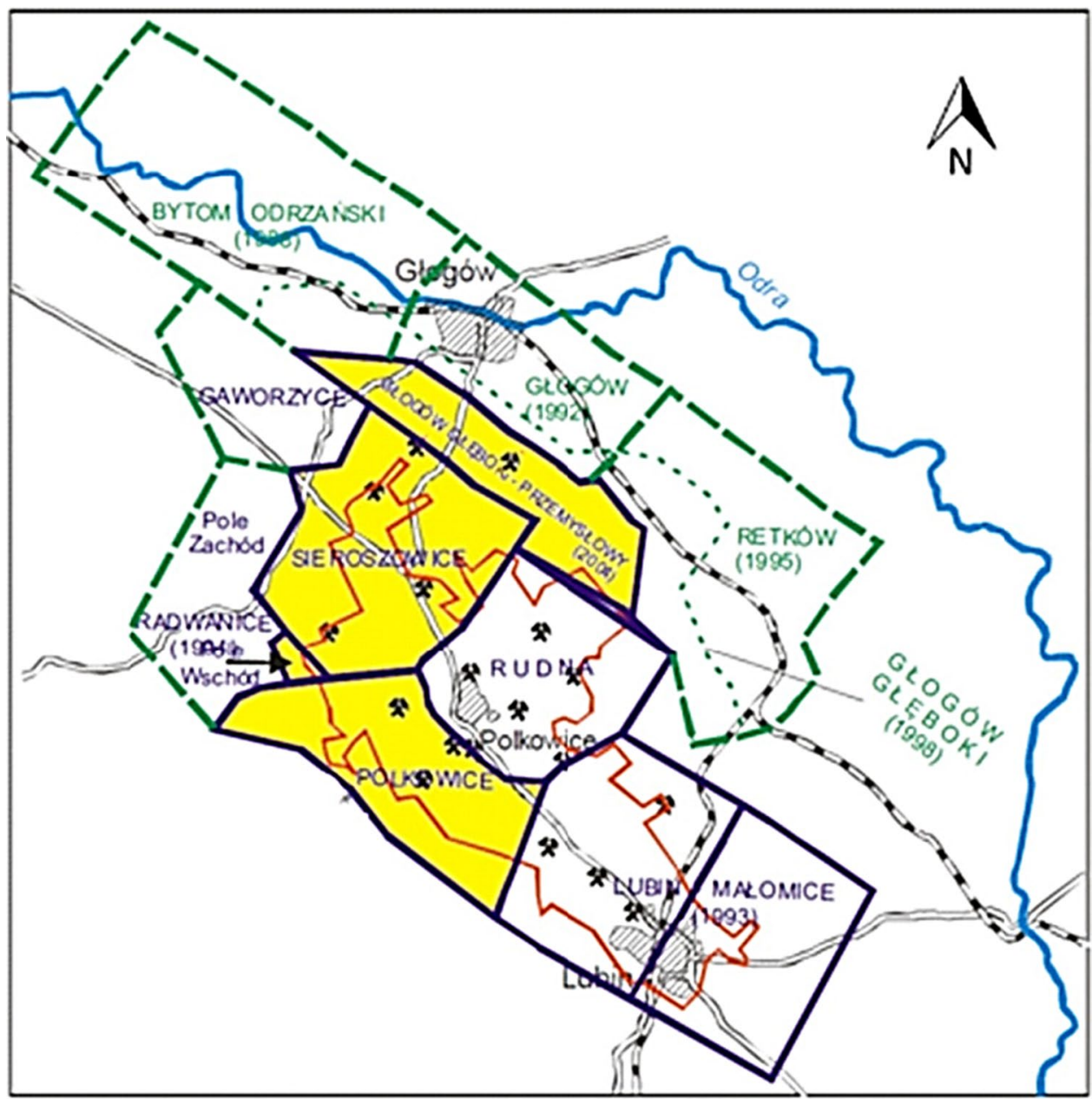

seismic anomaly. Therefore, the passive seismic tomography based on seismic events or ubiquitous seismic noise can be used for recognising and monitoring the stress in the rock mass. The data used in this method are collected and stored by the mine's seismic networks and enable calculation of the coordinates of the epicentres of the tremors and their energy.

Tomography is a method of studying the structure of the interior of objects based on the time of wave propagation and its amplitude (Maxwell and Young 1993; Aki and Richards 2009; Debski et al. 2018). The issue of passive tomography is not easy to solve, because the location and time of wave appearance are not known and then tomography becomes the so-called inversion task, in which there are many possible solutions for a given dataset (Tarantola 1987, 2005; Debski 2004, 2010, 2013).

The results of passive tomography are distributions mostly of the P-wave velocity; when the stress increases, the velocity increases (Debski and Young 1999, 2002; Dubinski and Mutke 2005; Czarny et al. 2019). Equally dangerous is the situation in which there is an increase in rock damage, which is manifested by a velocity decrease, often to values smaller than those recorded before. On this basis, attempts have been made to use seismic tomography to predict changes in the rock mass, especially to identify seismic risks or rock bursts and to locate the seismic events more accurately (Dubinski and Mutke 2005; Mutke 2007; Banka 2009). In the case of an underground mine, where data are obtained from seismological networks, there are much less unknown parameters. The basic difficulty is the parameterisation of the velocity model of the medium, which requires the use of an irregular grid and high density of seismic rays coverage (Debski and Young 1999; Lurka 2009; Czarny et al. 2019).

Studies and researches have shown that strong tremors' hypocentres are usually associated with high-velocity zones of the P-wave or with great gradients of its changes (Maxwell and Young 1994; Lurka 2009; Czarny et al. 2019). Zones with very low wave velocity generally correlate with zones with weak seismicity. They may also be formed as a result of past rock bursts and strong tremors that caused local destruction of rocks (Maxwell and Young 1993, 1994; Mutke et al. 2001). The layout of the velocity field is dynamic, especially clearly in the areas where exploitation is carried out. Therefore, it is best to perform threat analyses 
periodically and follow the directions of threat changes in correlation with the development of exploitation fronts. Seismic hazard occurs the most serious in a situation where the foci of strong tremors are located close to active exploitation fronts (Mutke 2007). Therefore, information about potential locations of tremors is very important from the point of view of prevention used to reduce the risk of rock bursts. Thus, passive tomography enables the assessment and location of stress concentration areas. The calculated field of the P-wave velocity allows for identifying and monitoring the seismic hazard zones.

The passive seismic tomography based on seismic events can be used to control a state of the stress in exploitation panels to estimate the efficiency of blasting or a need to use it. The article attempted to apply the passive seismic tomography based on seismic events to assess the efficiency of group winning-blasting in reducing the seismic hazard. Therefore, the seismic activity and archival tomography results were analysed to verify the assumption that the more provoked tremors took place in high-velocity zones, the more successful preventive blasting was. The seismic wave velocity and anomaly, obtained from tomographic results, were investigated concerning the location, number and energy of provoked seismic events. The \#3 mining division of high rock burst hazard in the Polkowice-Sieroszowice mine was studied. The investigation concerned the 2006-2017 years, during which seismic tomography tests were performed every three months.

\section{Study area, dataset and method}

The investigation covered 12 years in the \#3 mining division of the Polkowice-Sieroszowice mine (Fig. 2), which consisted of 2 fields: \#3/1 and \#3/2, situated at the depth of 660-850 $\mathrm{m}$. The \#3 division was situated in the north-east part of Polkowice mining field (Fig. 1); the \#3/1 field occupied the northern part, while the $\# 3 / 2$ posed the southern part of the division (Fig. 2). The \#3/1 field was limited as follows: from the north with the other mining field and borders with the Rudna I mining area; to the east by a line marking the range of the Polkowice mining area; to the south, south-west and west by a line dividing the \#3 mining division into \#3/1 and \#3/2 fields. The \#3/2 field was restricted as follows: from the north with the other mining field, to the north-east by a line dividing the \#3 area into \#3/1 and \#3/2 fields; from the southeast, by a line of 2019 and 2018 exploitation range; from the south, south-west and west by a line running along the border of the \#3/1 field gobs from previous years.

Mining was conducted with the use of a room-and-pillar with the roof self-deflection technology. The area was not strongly faulted, and the deposit thickness changes from 1 to $3 \mathrm{~m}$. The highest strength was achieved by roof rocks up to $253 \mathrm{MPa}$, while the lowest was shown by the floor rocks, which was less than $65 \mathrm{MPa}$. Such a strength variability made the deposit prone to rock bursts. The mining division was characterized by high seismic activity and rock burst hazard. In years 2006-2016, 60 rock bursts occurred in the mine and 35 of them were noted in the \#3 division.

The dataset consisted of tremor epicentre coordinates and energy registered by the mine seismological network and the archival results of the passive tomography calculations.
Fig. 2 Mining workings in the \#3 mining division in the Polkowice mining field

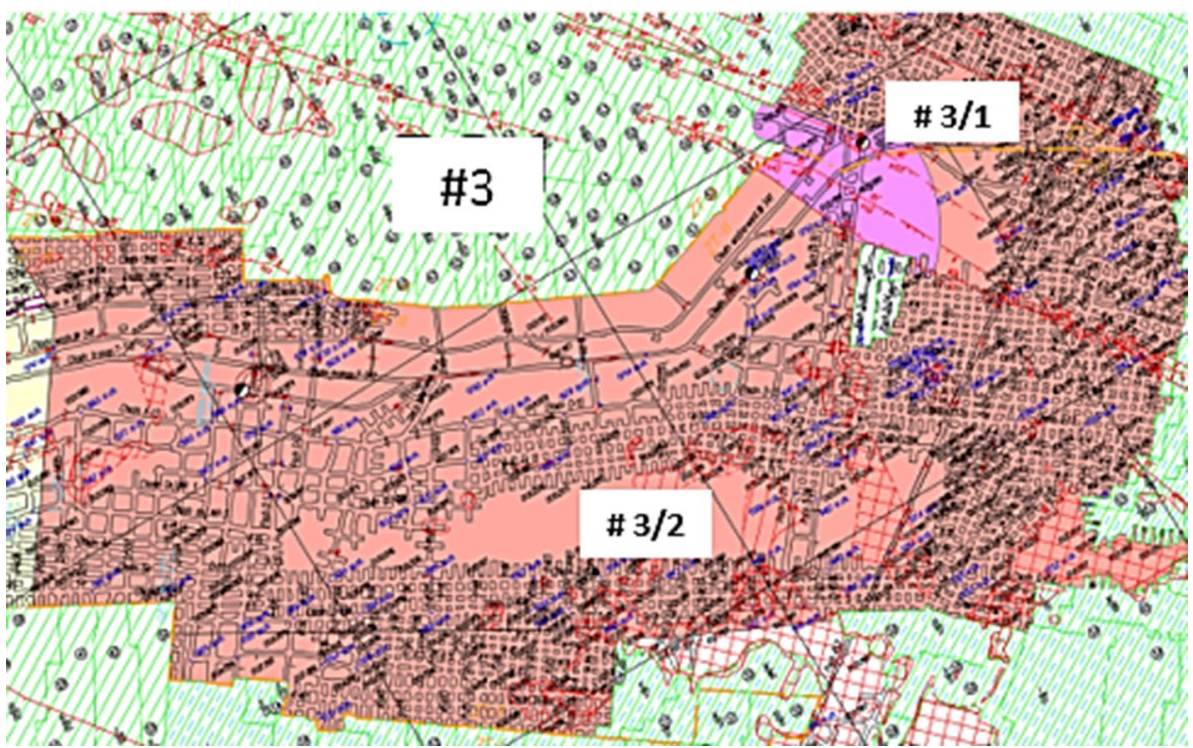


The passive seismic tomography is a method used in the Polkowice-Sieroszowice mine as a preliminary seismic risk forecasting tool. The basis is the specification of zones with the highest or lowest wave velocity and positive or negative seismic anomalies. In the practice applied in the \#3 division, the information about seismic tremors, which occurred in this area 2 or 3 months before the date of the tomographic calculation, was necessary for this purpose.

Deposit stress reduction is a technical procedure, e.g. exploitation of adjacent layers or blasting, which destroys the rock mass. It is aimed at reducing the capability of rocks to accumulate energy. The exploitation of adjacent layers (the less endangered ones) is one of the passive methods of rock burst prevention. Blasting is one of the active methods, among which group wining-blasting is the most successful in reducing the seismic hazard.

The passive tomography was used to assess the efficiency of blasting in seismic energy reduction. The number of provoked tremors appeared in the designated high-velocity and positive seismic anomaly zones and the number of those associated with the low-velocity zones and negative anomaly were found. Simultaneously, the efficiency of blasting to make the seismic energy release was calculated using the percentage of the number and energy of blasting-induced tremors.

\section{Results and discussion}

\section{Seismic activity}

Over 2006-2017 years in the \#3 division, the seismic activity was high (Table 1, Fig. 3). There were 6532 tremors with the energy of $5.1 \cdot 10^{9} \mathrm{~J}$. The most tremors, 947 , occurred in the 2015 year, and each year of the period there were 319 to

Table 1 Seismic activity in the \#3 mining division over 2006-2017 years

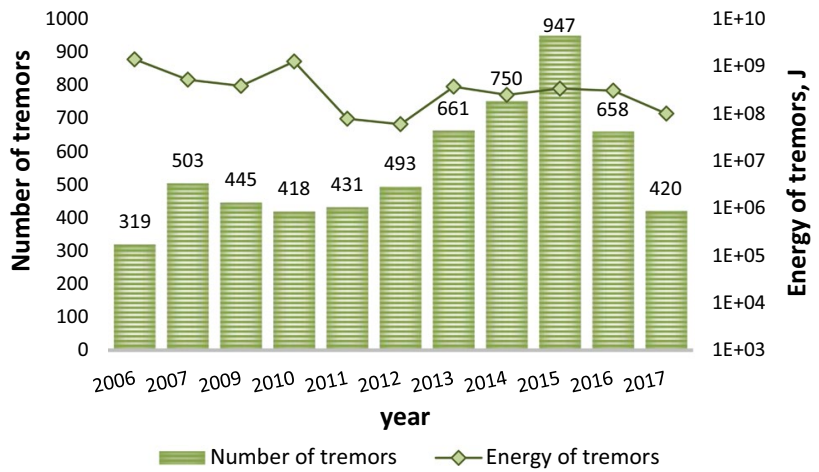

Fig. 3 The seismic activity in the \#3 mining division in 20062017 years

750 ones. The energy was also significant and changed from $5.8 \cdot 10^{7} \mathrm{~J}$ to $1.4 \cdot 10^{9} \mathrm{~J}$.

\section{Blasting-provoked tremors and rock bursts}

Between 2006 and 2017 years, 2080 provoked tremors with a total energy of $2.14 \cdot 10^{9} \mathrm{~J}$ were recorded. Table 2 and Fig. 4 present the annual numbers and energy of tremors. From 2006 to 2014, the number of phenomena remained at a similar level, ranging from 107 in 2011 to 187 in 2007. The breakthrough year was 2015 when the highest number of tremors occurred-338. The following years were characterized by a decreasing trend, reaching 47 provoked tremors in 2017. The course of the triggered total energy in individual years was slightly different. The highest value was observed for 2006, namely, 6.4.10 ${ }^{8} \mathrm{~J}$. Equally high energy $\left(6.0 \cdot 10^{8} \mathrm{~J}\right)$ was recorded in 2010 . Similarly to the number of tremors, after 2014 the total energy of seismic phenomena was increasingly lower and in 2017 it reached a minimum

Table 2 Blasting-induced (provoked) tremors in the \#3 mining division over 2006-2017 years

\begin{tabular}{|c|c|c|c|c|c|}
\hline \multirow{2}{*}{ Year } & \multirow{2}{*}{$\begin{array}{l}\text { Number of } \\
\text { tremors }\end{array}$} & \multirow{2}{*}{$\begin{array}{l}\text { Energy of } \\
\text { tremors, J }\end{array}$} & \multicolumn{3}{|c|}{ ion over 2006-2017 years } \\
\hline & & & Year & Number of tremors & Energy of tremors, $\mathrm{J}$ \\
\hline 2006 & 319 & $1.4 \cdot 10^{9}$ & 2006 & 120 & $6.4 \cdot 10^{8}$ \\
\hline 2007 & 503 & $5.0 \cdot 10^{8}$ & 2007 & 187 & $2.3 \cdot 10^{8}$ \\
\hline 2008 & 487 & $1.9 \cdot 10^{8}$ & 2008 & 150 & $7.0 \cdot 10^{7}$ \\
\hline 2009 & 445 & $3.7 \cdot 10^{8}$ & 2009 & 145 & $1.4 \cdot 10^{8}$ \\
\hline 2010 & 418 & $1.2 \cdot 10^{9}$ & 2010 & 147 & $5.9 \cdot 10^{8}$ \\
\hline 2011 & 431 & $7.6 \cdot 10^{7}$ & 2011 & 107 & $3.1 \cdot 10^{7}$ \\
\hline 2012 & 493 & $5.8 \cdot 10^{7}$ & 2012 & 159 & $1.6 \cdot 10^{7}$ \\
\hline 2013 & 661 & $3.6 \cdot 10^{8}$ & 2013 & 159 & $9.6 \cdot 10^{7}$ \\
\hline 2014 & 750 & $2.4 \cdot 10^{8}$ & 2014 & 168 & $8.8 \cdot 10^{7}$ \\
\hline 2015 & 947 & $3.3 \cdot 10^{8}$ & 2015 & 338 & $1.3 \cdot 10^{7}$ \\
\hline 2016 & 658 & $3.0 \cdot 10^{8}$ & 2016 & 261 & $7.5 \cdot 10^{7}$ \\
\hline 2017 & 420 & $9.6 \cdot 10^{7}$ & 2017 & 139 & $3.4 \cdot 10^{7}$ \\
\hline Total & 6532 & $5.1 \cdot 10^{9}$ & Total & 2080 & $2.14 \cdot 10^{9}$ \\
\hline
\end{tabular}




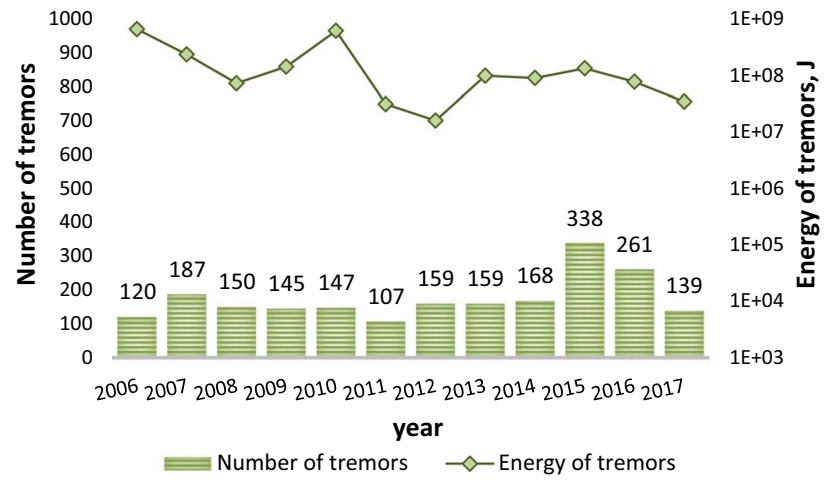

Fig. 4 Number and energy of blasting-induced tremors in the \#3 mining division in 2006-2017 years

Table 3 Efficiency of blasting in reducing seismic hazard in the \#3 mining division over 2006-2017 years

\begin{tabular}{lll}
\hline Year & $\begin{array}{l}\text { Efficiency for the number of } \\
\text { tremors, \% }\end{array}$ & $\begin{array}{l}\text { Efficiency for the } \\
\text { energy of tremors, } \\
\%\end{array}$ \\
\hline 2006 & 38 & 47 \\
2007 & 37 & 45 \\
2008 & 31 & 36 \\
2009 & 33 & 37 \\
2010 & 35 & 49 \\
2011 & 25 & 40 \\
2012 & 32 & 27 \\
2013 & 24 & 27 \\
2014 & 22 & 36 \\
2015 & 36 & 40 \\
2016 & 40 & 25 \\
2017 & 33 & 35 \\
Average & 32 & 42 \\
\hline
\end{tabular}

of 3.4.107 J. Over 2006-2017 years 24 provoked rock bursts took place.

\section{The efficiency of blasting in reducing the seismic hazard}

Tremors are provoked to reduce stored elastic energy in the rock mass. This allows, to some extent, the occurrence of spontaneous tremors, which are one of the most serious threats in underground copper ore mines in Poland, to be limited. Table 3 presents the efficiency of active prevention measure concerning the number and energy of tremors. The percentage of provoked tremors in the total number of all seismic events occurring in any year did not exceed $40 \%$. The highest efficiency of prevention was achieved in 2016 when out of 658 seismic phenomena 261 were provoked. The lowest efficiency of provocation, $22 \%$, was recorded in 2014. At the turn of the analysed period, relatively good provocation efficiency was achieved for nine years. In total, 6,632 tremors occurred, with $32 \%$ being provoked. More important, however, is the efficiency of tremor provocation determined in terms of total energy. Similarly, in this case, for 9 years it amounted to over 30\%; however, it is distinguished by higher values than in the case of the number of tremors provoked, reaching a maximum of $49 \%$ in 2010 . The total energy efficiency of prevention was $42 \%$ for the analysed period. Therefore, the efficiency of the applied active prevention in the form of group blasting in the years 2006-2017 for the \#3 division can be assessed as relatively satisfactory. Moreover, the efficiency for rock burst provocation was $40 \%$.

\section{Assessment of elastic energy reduction efficiency using passive seismic tomography}

An attempt was made to assess the reduction in energy stored in the rock mass with the use of passive seismic tomography. In this method, potential zones of increased seismic risk, i.e. zones with the particularly high $\mathrm{P}$-wave velocity and high seismic anomalies, are determined based on spontaneous tremors. These zones define areas of stress accumulation in the rock mass. Moreover, areas of low wave velocities, and thus of high negative anomalies, are also identified, which may be a reflection of low or reduced stresses. The efficiency of blasting in reducing seismic risk has been calculated in two ways: (1) as a percentage of provoked tremors located in zones with the high P-wave velocity and positive seismic anomaly (e.g. Fig. 7) and (2) as a percentage of the number and energy of provoked tremors in the number and energy of all tremors in the given zone (e.g. Figs. 8, 9). It has been verified whether the tremors associated with blasting occurred in the high-velocity zones of the seismic wave or the low-velocity zones.

In the \#3 mining division, the passive seismic tomography measurements were done every two months on average. 64 contour maps of P-wave velocity and seismic anomaly obtained in 2006-2017 years as well as 516 zones of high and low wave velocity and positive and negative seismic anomaly were studied. Below, the results of seven exemplary analyses of provoked tremors location and energy were depicted; one analysis was done in the 2006 year, and six were performed in 2010. The results of the analysis carried out in January 2010 are illustrated in Figs. 5 and 6. In the 2006 year, 3 passive tomography measurements were performed. Based on the first one, dated 20 April, 5 zones (I, II, III, IV and V) with high seismic P-wave velocity were determined. The I zone was mainly gobs. There was one provoked tremor with the energy of $10^{5} \mathrm{~J}$. Another provoked tremor took place in the IV zone, which was also located in the gobs. This zone was characterized by the highest wave velocity reaching $6500 \mathrm{~m} / \mathrm{s}$ and 


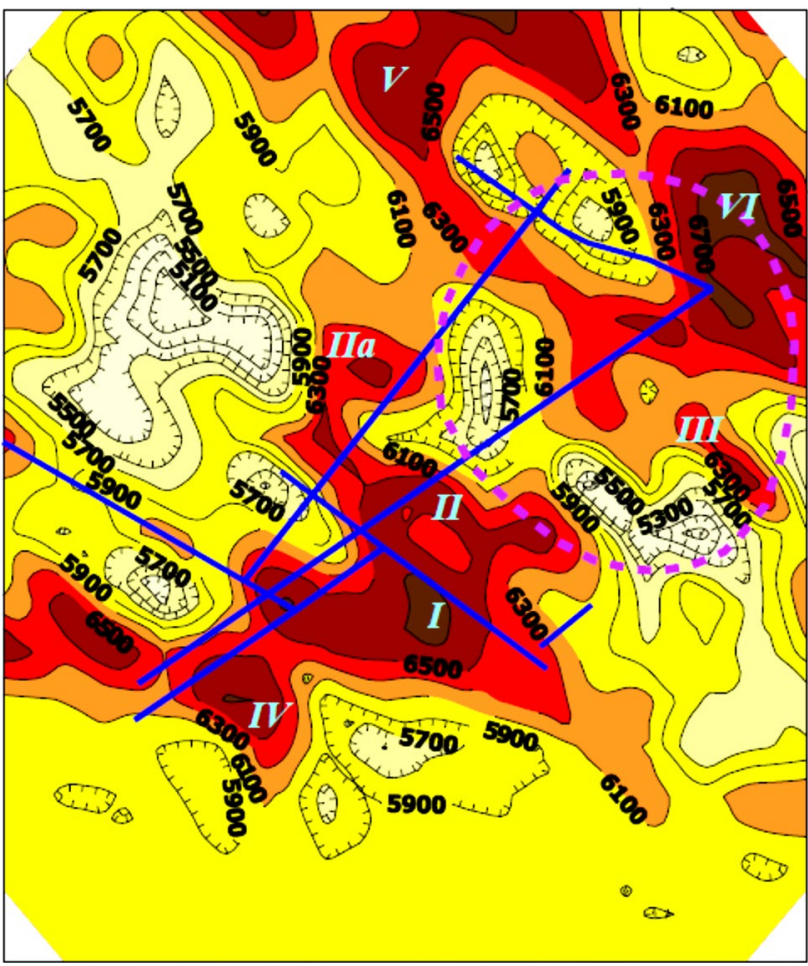

Fig. 5 P-wave velocity contour map calculated with passive seismic tomography for the 7th of January 2010 in the \#3 mining division. Seven zones (I, II, II a, III, IV, V and VI) of high P-wave velocity are marked. In each of the I, II and III zone, one provoked tremor occurred. Two provoked tremors occurred between II and II a zones, where the P-wave velocity was low. The blue lines represent main inclined drifts and mining workings, and the dashed violet line illustrates boundaries of the protective pillar of shafts

the positive seismic anomaly of $7 \%$. The other two provoked tremors took place in the $\mathrm{V}$ zone. These were high-energy ones with a total energy of $1.6 \cdot 10^{6} \mathrm{~J}$, and one of them caused a rock burst. For this measurement, $100 \%$ of the provoked tremors occurred in high-velocity zones. In 2010, the measurements were performed every two months. On January the 7th, seven high-velocity zones were designated: I, II, II a, III, IV, V and VI (Fig. 5), to which 3 among 8 provoked tremors were assigned. These were single occurrences in the I zone $(6800 \mathrm{~m} / \mathrm{s}$, anomaly of $11 \%)$ located in the undisturbed rock mass ahead of the front, in the II zone $(6500 \mathrm{~m} / \mathrm{s}$, seismic anomaly of $8 \%$ ) located near the protective pillar of shafts and the zone III $(6500 \mathrm{~m} / \mathrm{s}$, seismic anomaly of $7 \%)$ located on the boundary between the gobs and the cut-off deposit (Figs. 5 and 6). Two provoked tremors with energies of $10^{3} \mathrm{~J}$ and $10^{4} \mathrm{~J}$ occurred in the zone of low P-wave velocity located between II and II a zones (5100 m/s) (Fig. 5) and the negative seismic anomaly of -11\% (Fig. 6), located between two main inclined drifts. In the tomographic measurement on March 7, seven high-velocity zones were determined. The provoked tremors occurred mainly in the $\mathrm{V}-\mathrm{V}$ a zones, located on the boundary

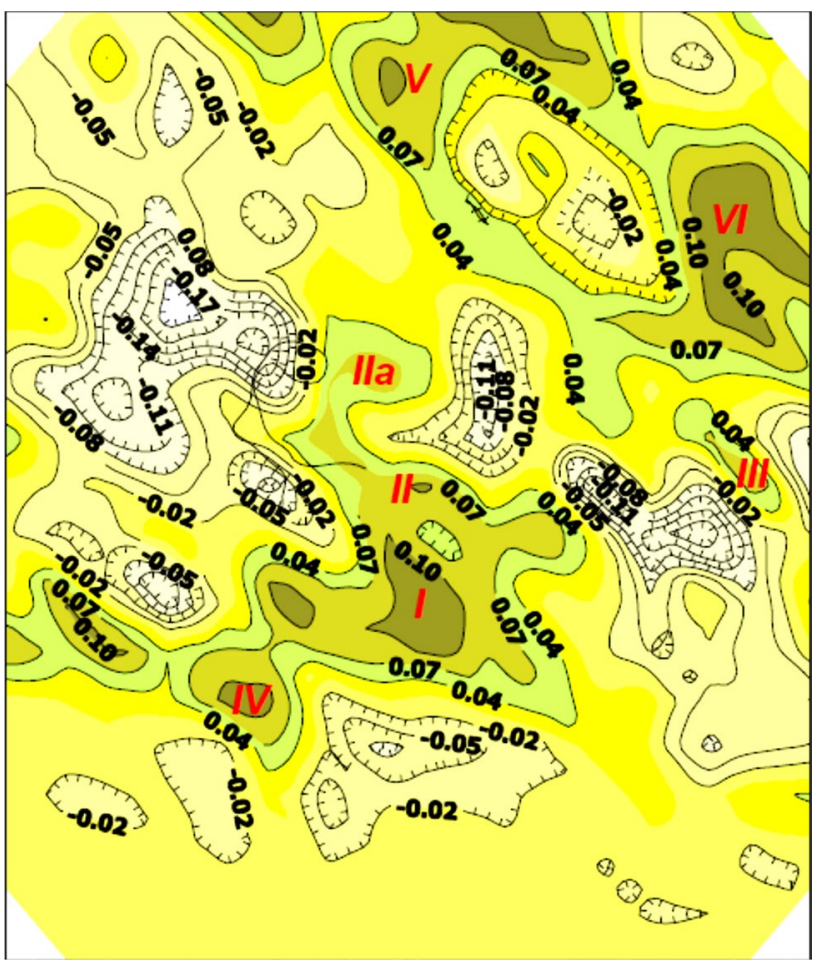

Fig. 6 Seismic anomaly contour map calculated with passive tomography for the 7th of January 2010 in the \#3 mining division. Seven zones (I, II, II a, III, IV, V and VI) of the positive seismic anomaly are marked. In each of the I, II and III zone, one provoked tremor occurred. Two provoked tremors occurred between II and II a zones, where the seismic anomaly was negative

of the gobs and undisturbed rock mass. The total energy of these tremors achieved $6.0 \cdot 10^{5} \mathrm{~J}$. Such tremors also occurred in the VI zone (on the boundary of the gobs and cut-off deposit) and the III zone (on the boundary of the cut-off deposit). These three zones were characterized by the same maximum P-wave velocity of $6800 \mathrm{~m} / \mathrm{s} .80 \%$ of the provoked tremors occurred in these zones. In the case of the measurement carried out on May 7, only one provoked tremor was located within one of the seven high-velocity zones; it took place in the undisturbed rock mass (the VI-VI a zones), and its energy was $3.2 \cdot 10^{4} \mathrm{~J}$. This tremor accounted for $20 \%$ of those provoked at that time. For the analysis of the tomographic results obtained on July 7 , nine provoked tremors were taken into account, of which six occurred in two of the high-velocity zones. It was II zone located in the area of the shaft's protective pillar and the VII zone assigned to the gobs. Both zones were characterized by high seismic anomalies of $11 \%$. In the investigation of September 7, the VI-VI a zones of high velocity of $6500-6800 \mathrm{~m} / \mathrm{s}$ and the positive seismic anomaly of $7-10 \%$ were determined in the undisturbed rock mass. In these zones, 10 tremors were provoked, which posed $71 \%$, and most of them were of $10^{7} \mathrm{~J}$ energy. The last survey carried out in 2010 identified seven high-velocity zones, but provoked tremors were recorded only 
Fig. 7 The average percentage of provoked tremors located in high-velocity zones in the \#3 mining division in 20062017 years

Fig. 8 The average efficiency of provocation for the number of tremors in the \#3 mining division in 2006-2017 years

Fig. 9 The average efficiency of provocation for the energy of tremors in the \#3 mining division in 2006-2017 years
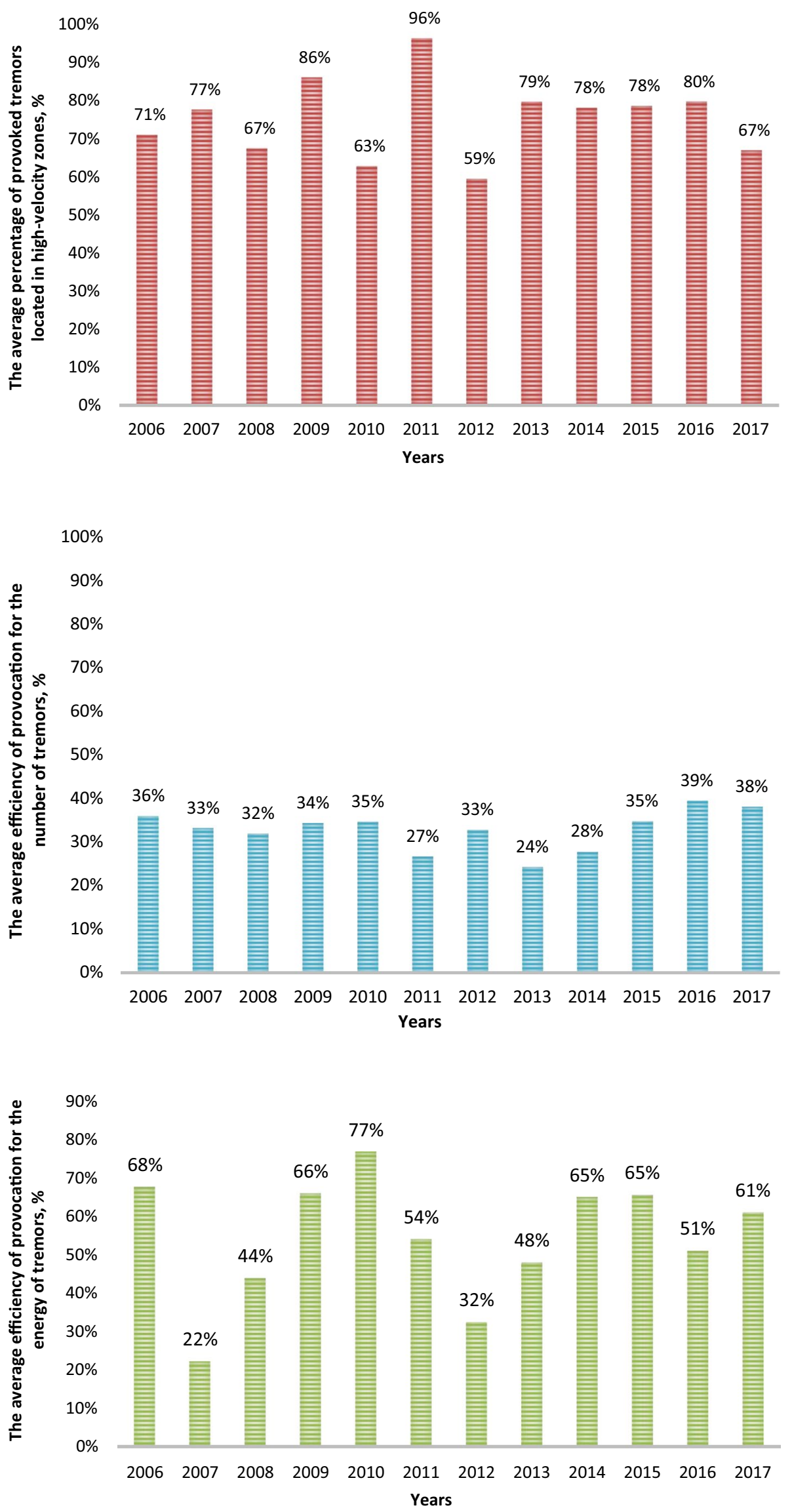
in three of them: in the central part of the protective pillar (the II zone), on the boundary of the gobs and cut-off deposit (the VI-VI a zones) and in the VII zone, far from the exploitation front. The total energy of those tremors did not exceed $10^{4} \mathrm{~J}$.

The efficiency of blasting in reducing the seismic activity as an average percentage of provoked tremors located in zones of the high P-wave velocity in the \#3 division over the 2006-2017 period is presented in Fig. 7. While the percentage of the number and energy of provoked tremors in the number and energy of all tremors in the given zone, describing such efficiency is illustrated in Figs. 8 and 9, respectiv ely.

In the \#3 division, the provoked tremors related to each of the tomographic measurements constituted on average $33 \%$. In 2009 and 2016, the highest values of $51 \%$ could be observed. In the case of rock burst prevention, not only the number of provoked tremors concerning spontaneous ones is important, but also their total energy. In this respect, the percentages were very diverse and ranged from 1 to $99 \%$. The average value determined for all studies was set at $54 \%$. It can therefore be considered that the prevention applied was relatively efficient, taking into account both the number and the cumulative energy of the tremors. Based on the results of the passive tomography, it was noted that in each measurement $60 \%$ of the provoked tremors were located within the zones of high-velocity seismic $\mathrm{P}$-wave propagation. Moreover, it was noted that for 17 measurements their location in high-velocity zones was $90 \%$. There were single measurements for which this value was lower, e.g. in 2006, 2011 or 2016 . However, they constituted a small part, so the average of all studies was 74\%. Observing the annual average values for 8 years, they were higher than $70 \%$, and in 2011 the location of provoked tremors coincided 96\% with the location of high-velocity zones. The lowest value equal to $59 \%$ was found in 2012. No correlation was observed between the location of provoked tremors in high-velocity zones and the efficiency of rock burst prevention. More than a third of provoked seismic events were found within the zones of the high seismic positive anomaly. A few highenergy tremors occurred in zones of low P-wave velocity and negative seismic anomalies, which might have indicated the low efficiency of blasting works in reducing the seismic hazard.

\section{Conclusion}

1. The analysis of the seismic events between 2006 and 2017 shows that the \#3 mining division was one of the seismically active areas with a high number of rock bursts and tremors.

2. The efficiency of the active prevention in terms of the number of tremors averaged over the entire analysis period reached $33 \%$ and in terms of energy of tremors $54 \%$. It can therefore be concluded that the rock burst prevention in the period 2006-2017 in the \#3 division achieved satisfactory efficiency.

3. More optimistic results were obtained based on the analysis concerning the location of provoked tremors in zones with increased P-wave velocity, i.e. with a potentially high risk of rock bursts. Within the designated zones, $74 \%$ of the provoked tremors occurred, which indicates that they occurred in the relevant areas, i.e. those characterised by the excessive elastic energy.

4. It can therefore be concluded that the passive seismic tomography method, which has been used to assess the condition of the rock mass from 2005 to 2017, can also be used to determine the location of the potential reduction in the elastic energy stored in the rock mass, i.e. the place where a large amount of provoked energy is emitted.

\section{Compliance with ethical standards}

Conflict of interest The authors declare that there is no conflict of interests regarding the publication of this paper.

Open Access This article is licensed under a Creative Commons Attribution 4.0 International License, which permits use, sharing, adaptation, distribution and reproduction in any medium or format, as long as you give appropriate credit to the original author(s) and the source, provide a link to the Creative Commons licence, and indicate if changes were made. The images or other third party material in this article are included in the article's Creative Commons licence, unless indicated otherwise in a credit line to the material. If material is not included in the article's Creative Commons licence and your intended use is not permitted by statutory regulation or exceeds the permitted use, you will need to obtain permission directly from the copyright holder. To view a copy of this licence, visit http://creativecommons.org/licenses/by/4.0/.

\section{References}

Aki K, Richards PG (2009) Quantitative seismology. University Science Books, Sausalito, p 700

Banka P (2009) Passive seismic tomography-selected problems. Silesian University of Technology, Gliwice

Butra J (2010) Exploitation of the copper ore deposit under conditions of rock bursts and roof falls. KGHM Cuprum Sp. z o.o, Wroclaw

Czarny R, Marcak H, Nakata N, Pilecki Z, Isakow Z (2016) Monitoring velocity changes caused by underground coal mining using seismic noise. Pure Appl Geophys 173(6):1907-1916. https://doi. org/10.1007/s00024-015-1234-3

Czarny R, Pilecki Z, Nakata N, Pilecka E, Krawiec K, Harba P, Barnaś M (2019) 3D S-wave velocity imaging of a subsurface disturbed by mining using ambient seismic noise. Eng Geol 251:115-127. https://doi.org/10.1016/j.enggeo.2019.01.017

Debski W (2002) Imaging rock structure using acoustic waves: methods and algorithms. In: Ogasawara $\mathrm{H}$, Yanagidani T, Ando M 
(eds) Seismogenic process monitoring. CRC Press, Florida, pp 309-326

Debski W (2004) Application of Monte Carlo techniques for solving selected seismological inverse problems. Publications of the Institute of Geophysics Polish Academy of Science, Warsaw, p 207

Debski W (2010) Probabilistic inverse theory. Adv Geophys 52:1-102. https://doi.org/10.1016/S0065-2687(10)52001-6

Debski W (2013) Bayesian approach to tomographic imaging of rockmass velocity heterogeneities. Acta Geophys 61(6):1395-1436. https://doi.org/10.2478/s11600-013-0148-7

Debski W, Young R (1999) Enhanced velocity tomography: Practical method of combining velocity and attenuation parameters. Geophys Res Lett 26(21):3253-3256. https://doi.org/10.1029/1998G L010368

Debski W, Young R (2002) Tomographic imaging of thermally induced fractures in granite using Bayesian inversion. Pure Appl Geophys 159(1-3):277-307. https://doi. org/10.1007/978-3-0348-8179-1_13

Debski W, Cianciara A, Koziarz E (2018) Passive seismic tomography at Rudna copper ore mine. Geophysical Review 4:339-352

Dubinski J and Mutke G (2005) Study of temporal changes of P-wave velocity in Polish copper mines in high seismic activity zones. In: The 6th International Symposium on Rockburst and Seismicity in Mines. Perth. pp 631-634, https://doi.org/https://doi.org/10.36487 /ACG_repo/574_71

Dubinski J, Pilecki Z, Zuberek WM (eds) (2001) Badania geofizyczne w kopalniach [Geophysical surveying in mines]. IGSMiE PAN, Krakow, pp 1-526

Gibowicz SJ (2009) Seismicity induced by mining: recent research. Adv Geophys 51:1-563. https://doi.org/10.1016/S0065 -2687(09)05106-1

Gibowicz SJ, Kijko A (1994) An introduction to mining seismology. Academic Press, Cambridge, p 399

Kijewski P (ed) (2006) Monography of Polkowice-Sieroszowice Mining Plant. KGHM Cuprum Sp. Z O. O, Wroclaw Poland

Kormendi A, Bodoky T, Hermann L, Dianiska L, Kalman T (1986) Seismic measurements for safety in mines. Geophys Prospect 34(7):1022-1037
Lurka A (2009) Selected theoretical and practical problems of passive tomography in underground mining. Central Mining Institute, Katowice

Marcak H, Pilecki Z (2019) Assessment of the subsidence ratio be based on seismic noise measurements in mining terrain. Arch Min Sci 64(1):197-212. https://doi.org/10.24425/ams.2019.126280

Maxwell SC, Young RP (1993) Comparison between controlled source and passive source seismic velocity images. Bull Seismol Soc Am 83(6):1813-1834

Maxwell SC and Young RP (1994) Application of seismic tomography to induced seismicity investigations. In: Proceedings of Eurock '94, Balkema, Rotterdam.

Mutke G (2007) Ocena zagrożenia tąpaniami w kopalniach podziemnych uwzględniająca parametry drgań blisko ognisk wstrząsówdoświadczenia z polskich kopalń [Rockburst hazard prognosis for underground mines taking into consideration tremor parameters close to the tremor sources-experiences from Polish mines]. Gornictwo i Geoinżynieria [Mining and Geoengineering] 31(3/1):439-450

Mutke G, Lurka A, Mirek A, Bargiel K, Wrobel J (2001) Temporal changes in seismicity and passive tomography images: a case study of Rudna copper ore mine-Poland. V International Symposium Rockbursts and Seismicity in Mines. The South African Institute of Mining and Metallurgy, Johannesburg, pp 237-330

Nolet G (ed) (1987) Seismic tomography with applications in global seismology and exploration geophysics. Springer, Dodrecht, p 386

Szreder Z, Pilecki Z, Kłosinski J (2008) Effectiveness of recognition of exploitation edge influence with the help of profiling of attenuation and velocity of seismic wave. Gospod Surowcami Mineralnymi 24(2):215-226

Tarantola A (1987) Inverse problem theory: methods for data fitting and model parameter estimation. Elsevier, Amsterdam, p 613

Tarantola A (2005) Inverse problem theory and methods for model parameter estimation. Society for Industrial and Applied Mathematics, Philadelphia, p 342 